This is an author produced version of a paper published in ECOLOGICAL ENGINEERING. This paper has been peer-reviewed but does not include the journal pagination.

Citation for the published paper:

Persson, J. \& Wittgren, H.B. (2003) How Hydrological and hydraulic conditions affect performance of treatment wetlands. Ecological

Engineering. Volume: 21 Number: 4-5, pp 259-269. http://dx.doi.org/10.1016/j.ecoleng.2003.12.004

Access to the published version may require journal subscription.

Published with permission from: Elsevier Ltd.

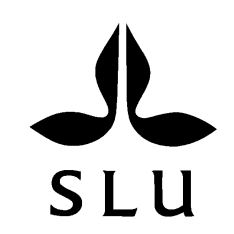

Epsilon Open Archive http://epsilon.slu.se 


\title{
How hydrological and hydraulic conditions affect performance of ponds
}

\author{
Jesper Persson ${ }^{\mathrm{a}, *}$, Hans B. Wittgren ${ }^{\mathrm{b}}$ \\ ${ }^{a}$ Department of Landscape Management and Horticulture Technology, Swedish University of Agricultural Sciences, \\ P.O. Box 66, SE-230 53 Alnarp, Sweden \\ b JTI, Institute of Agricultural and Environmental Engineering, P.O. Box 7033, SE-750 07 Uppsala, Sweden
}

Received 24 April 2003; received in revised form 1 December 2003; accepted 5 December 2003

\begin{abstract}
During the 1990s there has been a growing interest in (re)constructed wetlands and ponds for treatment of agricultural runoff, sewage water, and stormwater. Some of these facilities, however, are poorly designed in terms of hydrological and hydraulic performance, which strongly affects their treatment capacity. This paper gives an overview of the present knowledge regarding pond hydraulics in terms of effective volume ratio and dispersion. The importance of these parameters is demonstrated by modelling of nitrogen removal in 13 ponds of different design. The results show that effective volume ratio has a clear influence, which increases when removal rate coefficients increase, while dispersion is of minor importance for removal efficiency. Finally, the concept of hydraulic efficiency is discussed in the light of these results.
\end{abstract}

(C) 2004 Elsevier B.V. All rights reserved.

Keywords: Design; Efficiency; Hydraulic; Nitrogen; Performance; Pond; Tank-in-series model; Wetland

\section{Introduction}

Design of constructed ponds generally requires a multidisciplinary input of knowledge involving biological and ecological sciences, aquatic chemistry, landscape architecture, hydrological engineering, and flow hydraulics. In addition to quality improvements, ponds are often used as water features to serve as part of the urban and rural landform and to provide recreational amenities. Problems occur, however, when ponds have been constructed with insufficient

\footnotetext{
* Corresponding author.

E-mail addresses: jesper.persson@1t.slu.se (J. Persson), hb.wittgren@jti.slu.se (H.B. Wittgren).
}

consideration given to their requirements for proper hydrological and hydraulic design. Unsatisfactory hydraulic control is one of the causal factors in poor performance of constructed ponds as water pollution control facilities (Reed et al., 1995).

Constructed ponds are mainly used to treat agricultural runoff, sewage water, and stormwater. The treatment of the first two types of water aims mainly at reducing nitrogen, carbon and phosphorus, while treatment of stormwater often aims at reducing the level of suspended solids and heavy metals. Existing or reconstructed ponds are sometimes also used for these purposes.

Most of the ponds constructed in Scandinavia can also be regarded as wetlands, depending on which 


\begin{tabular}{|ll|}
\hline \multicolumn{2}{|l|}{ Nomenclature } \\
$A$ & area $\left(\mathrm{L}^{2}\right)$ \\
$c$ & concentration $\left(\mathrm{ML}^{-3}\right)$ \\
$d$ & dispersion coefficient $\left(\mathrm{L}^{2} \mathrm{~T}^{-1}\right)$ \\
$D$ & dispersion number \\
$e$ & effective volume ratio \\
$E$ & dynamic sediment trap efficiency \\
$h$ & depth $(\mathrm{L})$ \\
$k$ & volume-based removal rate constant \\
& (T $\left.\mathrm{T}^{-1}\right)$ \\
$k_{\mathrm{aT}}$ & area-based temperature-dependent \\
& removal rate constant $\left(\mathrm{L} \mathrm{T}^{-1}\right)$ \\
$\lambda$ & hydraulic efficiency \\
$L$ & length $(\mathrm{L})$ \\
$N$ & number of cells \\
$n$ & pond settling performance constant \\
$P e$ & Peclet number \\
$\sigma^{2}$ & variance $\left(\mathrm{T}^{2}\right)$ \\
$Q$ & flow $\left(\mathrm{L}^{3} \mathrm{~T}^{-1}\right)$ \\
$t_{\text {mean }}$ & mean residence time $(\mathrm{T})$ \\
$t_{\mathrm{n}}$ & nominal residence time $(\mathrm{T})$ \\
$t_{\mathrm{p}}$ & peak time $(\mathrm{T})$ \\
$t$ & time $(\mathrm{T})$ \\
$v$ & kinematic viscosity $\left(\mathrm{L}^{2} \mathrm{~T}^{-1}\right)$ \\
$U$ & velocity $\left(\mathrm{L} \mathrm{T}^{-1}\right)$ \\
$W$ & width $(\mathrm{L})$ \\
$w$ & particle fall velocity $\left(\mathrm{L} \mathrm{T}^{-1}\right)$ \\
$V$ & volume $\left(\mathrm{L}^{3}\right)$ \\
$V_{\text {eff }}$ & effective volume $\left(\mathrm{L}^{3}\right)$ \\
$\left.V_{\text {total }}\right)$ & total volume $\left(\mathrm{L}^{3}\right)$ \\
$x$ & length in $x$-direction $(\mathrm{L})$ \\
& \\
&
\end{tabular}

definition one uses. The term "wetland" includes a wide range of ecosystems, from areas that are never flooded (e.g. saturated soil) to areas that are deeply flooded all of the time, like ponds or small lakes. The systems described in this article are defined as ponds, but could in a wider sense also be regarded as surface flow wetlands.

The background of this article started partly when the first author was asked to present the state-of-the-art on pond hydraulics at the conference New Wetlands in Agricultural Areas-Restoration, Construction and Impact on Nutrient Reduction and Biodiversity in Lund, Sweden (Persson, 2001). The audience mainly consisted of biologists and the speech was of a more general character. The other incitement to write this article is to continue the theoretical discussion of how hydraulic efficiency ought to be understood. During 1998 the first author spent several months with a research group at Monash University to finish a work on hydraulic efficiency in ponds. The aim was to develop a method that linked hydraulic efficiency in both ponds and similar surface flow wetlands, to removal of nutrients and suspended solids (including heavy metals). This could then be used as a general method to compare and optimise pond layouts (Persson et al., 1999). The paper from the wetland conference was therefore further developed, and added to an investigation of how dispersion and effective volume ratio effects nitrogen removal according to the first-order kinetics model.

The aim of this paper is firstly to give an introduction to pond hydraulics, focusing on factors that affect hydrological and hydraulic conditions. Secondly, to investigate the effects dispersion and effective volume ratio has on nitrogen removal and relates that to the discussion on the use of hydraulic efficiency as a method to compare different designs. The focus in the article is on nitrogen removal, which is central for improving the quality of water originating from agricultural areas.

The beginning of the paper describes how hydrology and hydraulic conditions influence the water treatment processes. Next, emphasis is placed on how pond hydraulics can be understood. This part is devoted to a detailed description of effective volume ratio and dispersion. The paper then discusses how design can be used to optimise effective volume ratio and dispersion, and how different designs can be compared by means of a hydraulic efficiency factor. Finally the paper analyses how effective volume (area) ratio and degree of dispersion affects nitrogen removal for a number of ponds of different design.

\section{Models for pollutant removal}

The tanks-in-series (TIS) model (Eq. (1)) is commonly used for modelling of pollutant removal in ponds and wetlands (Kadlec and Knight, 1996). The model represents a series of continuously stirred tank reactors (CSTRs) where a substance is removed in 
each tank according to first-order kinetics. The number of tanks, $N$, represents the degree of mixing. A high value of $N$ means a small degree of dispersion, i.e., a plug flow reactor (PFR), while $N=1$ defines a completely mixed reactor.

$$
\frac{C_{\text {out }}}{C_{\text {in }}}=\left(\frac{1}{1+\left(k t_{\mathrm{n}} / N\right)}\right)^{N}
$$

The theoretical or nominal residence time is defined by Eq. (2), and is increased by either an increase of the total volume or a decrease of the hydrological load.

$t_{\mathrm{n}}=\frac{V}{Q}$

The model (Eqs. (1) and (2)) illustrates the importance of hydrological conditions for pollutant removal. It also shows that there are different relations between residence time and pollutant removal, depending on whether we are interested in relative or absolute removal. The relative pollutant removal rate; $\left(C_{\text {in }}-C_{\text {out }}\right) / C_{\text {in }}$, increases with increasing residence time, while the absolute pollutant removal rate, $\left(C_{\text {in }}-\right.$ $\left.C_{\text {out }}\right) \times Q$, increases with decreasing residence time.

While Eq. (1) is typically used to describe removal of soluble pollutants, e.g., nitrogen, similar principles can also be found in models for removal of suspended solids. In Eq. (3) a model for dynamic sediment trap efficiency, $E$, is shown (EPA, 1986). The equation shows that the removal efficiency of suspended solids is dependent on particle fall velocity, $w$; settling basin area, $A$; flow, $Q$; and pond settling performance constant, $n$.

$E=1-\left(1-\frac{w A}{n Q}\right)^{-n}$

\section{Effective volume ratio}

Until now, the residence time under stationary flow conditions has been equal to the nominal residence time, defined in Eq. (2). In reality this is never the case, even under stationary flow conditions. The actual residence time, defined as mean residence time, $t_{\mathrm{m}}$, is always less than the nominal residence time, $t_{\mathrm{n}}$ (Fig. 1).

The residence time of a pond can be analysed with a tracer test, which produces a tracer concentration versus time distribution. Under plug flow conditions,

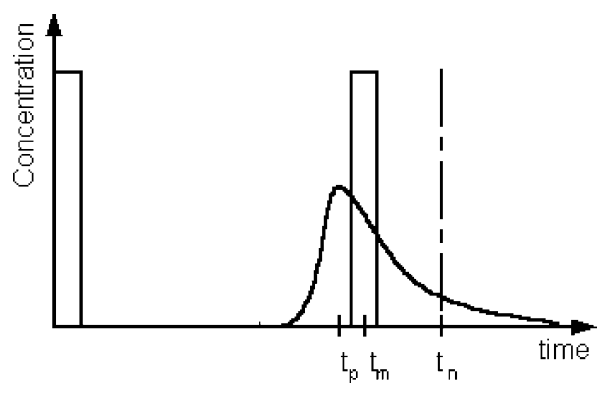

Fig. 1. Illustration of tracer concentration time distribution, where $t_{\mathrm{p}}$ is peak time for the concentration curve and $t_{\mathrm{m}}$ the mean residence time for the curve, in the case of the response under plug flow conditions. The nominal residence time, $t_{\mathrm{n}}$, is always larger than the mean residence time.

the concentration versus time distribution is simply a spike with a very small standard deviation about the mean residence time, $t_{\mathrm{m}}$, as shown in Fig. 1. The mean residence time is defined as the centroid of the RTD, where the RTD function, $f(t)$, is represented by the concentration or mass (Eq. (4)). This suggests that all individual parcels of tracer entering the pond experience a similar period of residence. However, pure plug flow conditions never occur in natural systems, which rather produce concentration versus time distributions with more or less deviation, i.e., more or less dispersion.

$t_{\text {mean }}=\frac{\int_{0}^{\infty} t f(t) \mathrm{d} t}{\int_{0}^{\infty} f(t) \mathrm{d} t}$

To better understand and discuss the relation between mean and nominal residence times, one can multiply the residence times by the flow, which gives us the relation between two volumes, the effective and total volume (Eq. (5)).

$e=\frac{V_{\text {eff }}}{V_{\text {total }}}=\frac{t_{\mathrm{m}}}{t_{\mathrm{n}}}$

The effective volume ratio, $e$, is linked to length and width, but is also affected by factors as wind. Thackston et al. (1987) carried out a series of experiments on large shallow ponds around $60-600,000 \mathrm{~m}^{3}$ and developed a model to calculate the effective volume ratio (Eq. (6)).

$e=0.84\left[1-e^{(-0.59(L / W))}\right]$ 


\section{Dispersion}

Dispersion is a measure of the degree of mixing in a pond. Its effect on pollutant removal is two-fold. If dispersion increases, the concentration of nutrient decreases, which in turn leads to lower removal efficiency. Further, a large dispersion represents a large variance in the concentration versus time distribution, which means that some of the water packages will move fast through the pond while some will travel more slowly.

Fick's second law, Eq. (7), defines dispersion. It consists of both molecular and turbulent diffusion, but also includes water movements in space.

$\frac{\partial c}{\partial t}=d \frac{\partial^{2} c}{\partial x^{2}}$

A complementary measure of dispersion, often used in pond and wetland literature, is the dispersion number, which is equal to the inverted Peclet number (Eq. (8)). It describes the ratio between the advective transport and the dispersion.

$P e=\frac{1}{D}=\frac{U L}{d}$

A number of equations are found in the literature that determines the dispersion number for water bodies similar to ponds. Fischer (1967) developed, for streams with large width-to-depth ratio, an equation for the dispersion number (Eq. (9)). The expression describes dispersion as a function of geometry, kinematic viscosity, nominal residence time and depth, where the latter two are related to hydrological load.

$D=\frac{0.304\left[\sqrt{t_{\mathrm{n}} \nu W}(W+2 h)^{1.5}\right]}{(L h)^{1.5}}$

The residence time in Fischer's equation is of less importance than the depth and length-to-width ratio. In an example shown in Fig. 2a and b, a hypothetical pond with width $25 \mathrm{~m}$ is investigated. The length is changed between 25, 50 and $100 \mathrm{~m}$ (representing length-to-width ratios $1: 1,2: 1$ and 4:1), while the depth varies between 0.4 and $1 \mathrm{~m}$. The change in Peclet number due to residence time is notable up to $1-2$ days. In this context one ought to keep in mind that a change of Peclet number from 1 to 2 is considerably larger than from 5 to 10 , at least regarding the effects on pollutant removal (this will be discussed later). On the other hand, the Peclet number is very sensitive to variations in water depth or length-to-width ratio.

Polprasert and Bhattarai (1985) developed an equation similar to Eq. (9). Their study, however, is not fully representative since the result is based on two small pilot-scale ponds. Further examples of dispersion models are given by Arceivala (1981), who developed an equation where the dispersion number is a function only of the width. The equation is valid for ponds with width greater than $30 \mathrm{~m}$ or less than $10 \mathrm{~m}$. Nameche and Vasel (1998) developed an equation for basins that relates only to geometry:

$P e=0.35 \frac{L}{W}+0.012 \frac{L}{h}$

Using the Nameche and Vasel equation for the same hypothetical pond as described above, it can be noted that there is a minor degree of variation of the Peclet number when the depth changes between 1 and $0.4 \mathrm{~m}$ (see Fig. 2a and b). However, the Peclet number reacts to a larger extent to changes of length-to-width ratio, as in the case of Fischer's equation.

A brief analysis of the Fischer (Eq. (9)) and the Nameche and Vasel (Eq. (10)) equations for calculating the dispersion processes in ponds shows that the length-to-width ratio is a very important factor in both cases. According to Fischer, the depth is also important, whereas in Nameche and Vasel's equation the depth has a minor effect. The third factor, residence time, has however a rather marginal affect except for ponds with high hydrological load.

The equations above determine Peclet number, exclude vegetation. This, however, is not correct when we look at larger ponds and wetlands with dense vegetation. Here the effective volume will increase with increasing length-to-width ratio, but the amount of dispersion will not change correspondingly. The reason is that the lateral mixing is limited due to channelling, which means that the dispersion is determined by vertical movements and diffusion along the flow direction, where the latter is dominant. According to this, an increasing width for a given length adds more parallel channels without affecting the dispersion; (Kadlec and Knight, 1996). 

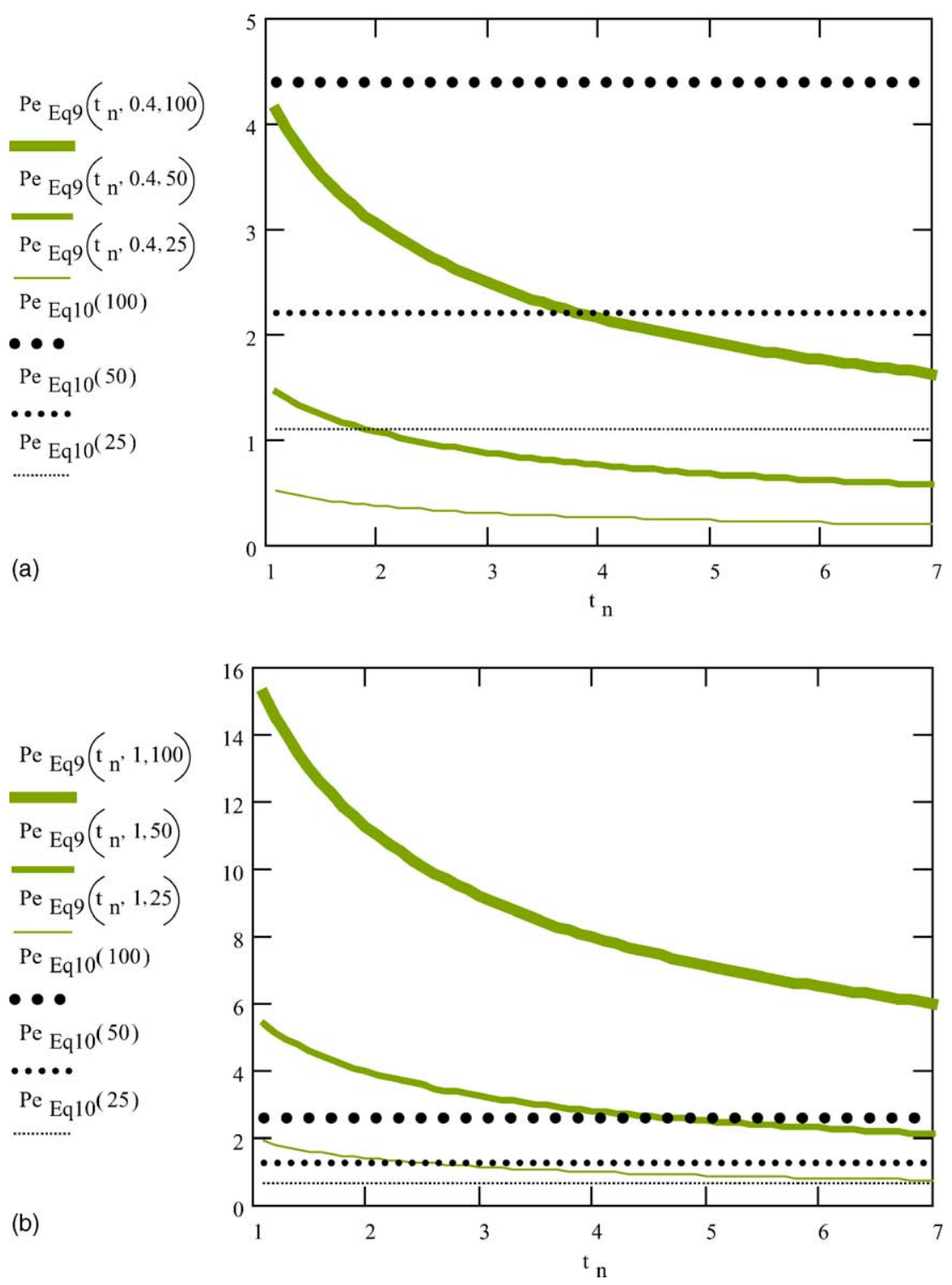

Fig. 2. (a) The Peclet number calculated according to Eqs. (9) and (10), for a hypothetical wetland with width $25 \mathrm{~m}$, depth $0.4 \mathrm{~m}$ and length varying between 25,50 and $100 \mathrm{~m}$ (representing length-to-width ratios 1:1, 2:1 and 4:1); and (b) the Peclet number calculated according to Eqs. (9) and (10), for a hypothetical wetland with width $25 \mathrm{~m}$, water temperature $20^{\circ} \mathrm{C}$ and depth $1.0 \mathrm{~m}$ and length varying between 25, 50 and $100 \mathrm{~m}$ (representing length-to-width ratios $1: 1,2: 1$ and 4:1).

\section{Impacts of variable hydrological load}

Till now stationary flow conditions have been assumed. In reality the hydrological load has a stochastic nature with sometimes large amplitudes. This is especially the case in urban areas or in small catchment areas. Stormwater and combined sewer overflows under treatment are two examples, where it is important to consider the nature of the flow conditions.

From a design perspective, three hydrological aspects are prominent when treating stormwater and combined sewer overflows. The first is to reduce the 
effect of re-suspension and erosion of sediment. A bypass upstream of the pond manages this. The result is that water will not enter the pond when it is full, but will pass around the pond. In some cases this is impossible due to lack of space, or unnecessary due to small amplitudes of flow peaks, but it should at least be considered. The term "hydrological effectiveness", introduced by Wong and Somes (1995), describes this aspect, and is defined as the ratio between the volume entering the pond and the total volume of runoff. The second aspect is to capture and retain flow peaks, which demands a retention volume. This storage is equal to the difference between the maximum volume that can be retained in the pond and the existing volume prior the flooding (which often is the same as the permanent pool). The third hydrological aspect is the need for a large volume within the pond, which increases the residence time. The consequence of these factors is that we do not have one nominal residence time, but rather a set of residence times. By analysing rain characteristics, volume, permanent pool and outlet configuration, probabilistic residence time distribution (PRTD) curves can be produced for each type of pond. These curves show the proportion of runoff (\%) as a function of residence time, i.e. the proportion of the water that has a larger residence time than e.g. $24 \mathrm{~h}$ or $72 \mathrm{~h}$, see Fig. 3. This information can than be used to size and design the residence volume, permanent pool and outlet configuration (Somes et al., 1998). The simulations are assuming plug-flow condition. Werner and Kadlec (2000) developed a stochastic model, also dealing with this problem, but assuming partial mixed flow.

The hydrological load does not affect only the residence time. Taking the removal of nitrogen as an example, also other conditions are influenced by the hydrological load:

- an increasing hydrological load may increase dispersion in the pond, and thus also the distribution of oxygen, which affects both nitrification and denitrification;

- a high hydrological load increases the water velocity, which can damage bio films, where a large fraction of coupled nitrification/denitrification typically takes place in a pond or wetland.

\section{How design affects hydraulic condition}

It has been shown that effective volume ratio and dispersion are dependent on pond length, width and depth. However, the equations described above (Eqs. (9) and (10)) are applicable only to less complex designs, which correspond to rectangular shaped basins. Even if the length-to-width ratio is fundamental, aspects such as inlet and outlet location and channelling due to vegetation or bottom topography have major impacts. Ten design aspects which can affect

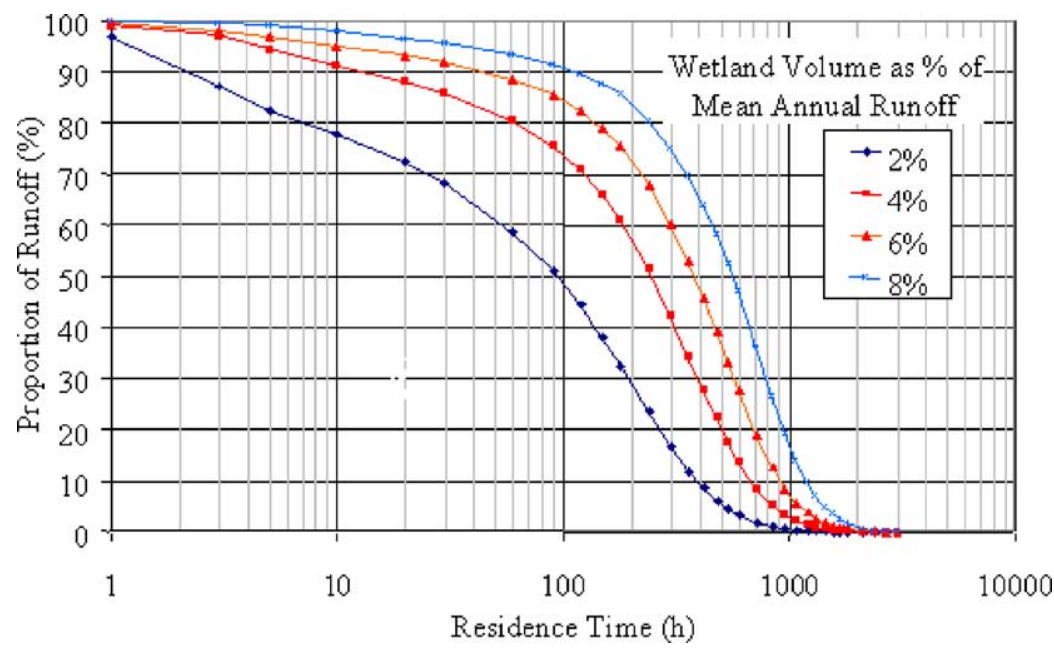

Fig. 3. Probabilistic residence time distribution (PRTD) curves of wetlands located in Melbourne, with different sizes and an outlet consisting of a weir. 
the hydraulic conditions and which often characterise the complexity of ponds are:

- profile (topography), i.e., flat or angled bottom;

- berm (topography);

- island (topography);

- depth;

- length-to-width ratio (horizontal plane);

- meandering (horizontal plane);

- form (horizontal plane), i.e., curved, circular, triangular or rectangular shape;

- baffles;

- inlet and outlet;

- vegetation, i.e., plant characteristics, density, location.

All of these 10 aspects influence all ponds, even if they are not planned or considered from the start. As has been described earlier, the effective volume is strongly correlated with the length-to-width ratio. The effective volume can, however, be increased or decreased by several of the 10 aspects above. In a pond with a given length-to-width ratio, the effective volume can be increased by a berm placed near the inlet, or by vegetation zones perpendicular to the flow direction. Channelling, on the other hand, causes a decrease of the effective volume. Fig. 4 shows how it is possible to change the effective volume ratio with different design solutions. In the first case a pond with a length-to-width ratio of 2:1 would, according to Eq. (6), have an effective volume ratio of $60 \%$. If however the present configuration were changed to a multiple inlet the ratio would probably increase to around $70-80 \%$. In the case where the pond has a length-to-width ratio of 5:1 but with the outlet placed close to the inlet, the ratio would probable be as low as $40 \%$, instead of nearly $80 \%$ if the outlet was placed at the other end of the pond (Persson, 2000). Finally it could be mentioned that wind can have a major impact on the hydraulic. This is however not a design issue and has therefore been excluded.

\section{How to compare different designs}

How do we know that one design has a better hydraulic performance than another? Persson et al.

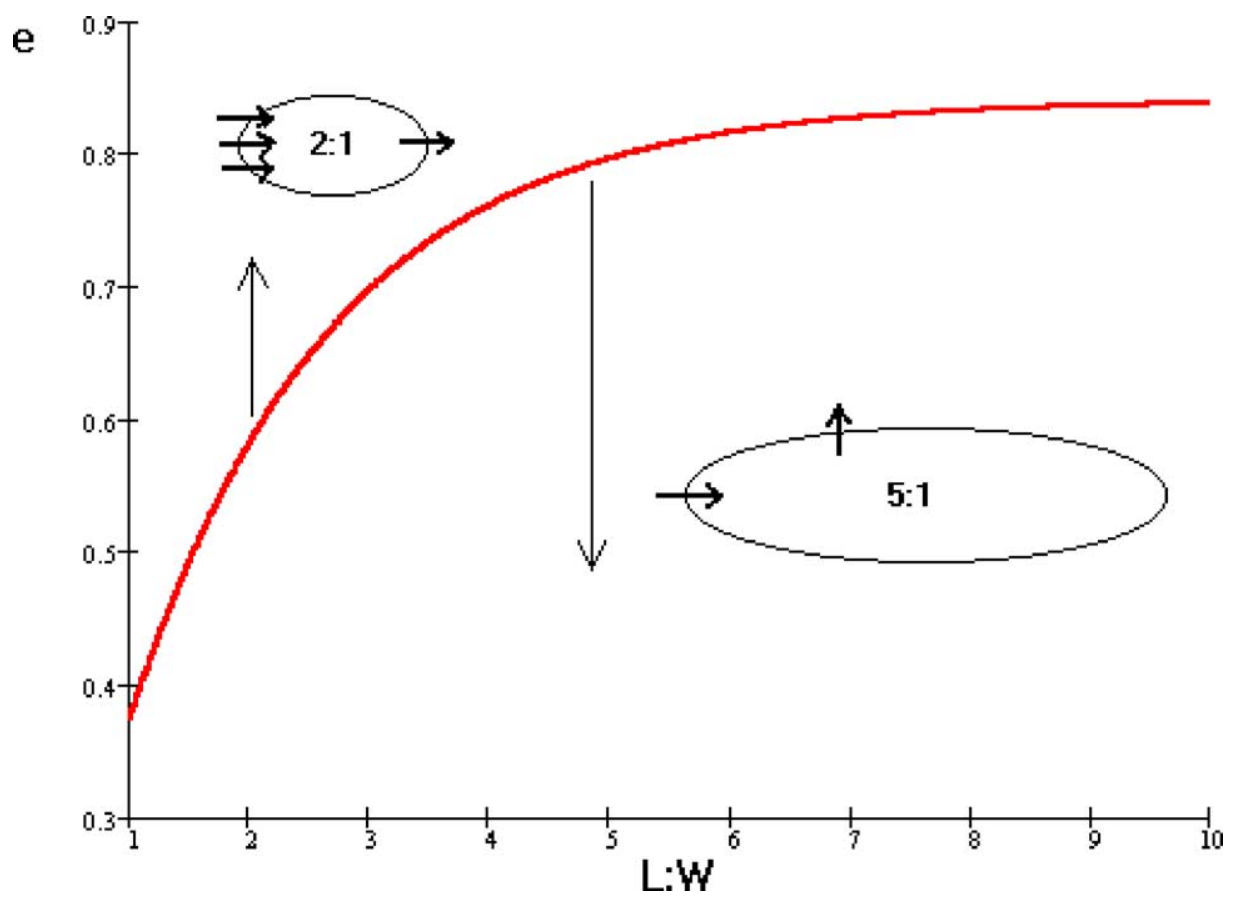

Fig. 4. How the effective volume ratio can be altered by smart or bad design solutions. The function shows the relation between effective volume ratio and the length-to-width ratio, according to Eq. (6). 
(1999) raised this question and developed a hydraulic efficiency factor, Eq. (11), which can be used for comparing different designs.

$\lambda=e\left(1-\frac{1}{N}\right)=\frac{t_{\mathrm{p}}}{t_{\mathrm{n}}}$

The $\lambda$ factor consists of two components: effective volume ratio and degree of mixing, expressed as (1 $(1 / N))$. Where $N$ is equal to the number of cells in the tank-in-series model Eq. (12) (Fogler, 1992):

$N=\frac{t_{\mathrm{n}}^{2}}{\sigma^{2}}$

An argument to involve degree of mixing is that it represents how large portion of the water that moves quickly or slowly, respectively through the pond in relation to the main flow, but also because mixing processes lowers the concentration of soluble pollutants. A large degree of mixing, therefore ought to result in poor removal efficiency. Which is also the case in e.g. the tank-in-series model Eq. (1). To decrease the effect of overestimation of the efficiency due to extremely high $N$-values, it was preferred to use the mixing factor $(1-(1 / N))$ instead of $N$. This also puts the mixing factor $(1-(1 / N))$ in an interval between 0 and 1. Both terms have, therefore, a range of $0-1$, giving equal weight to the effective volume ratio and the mixing factor. The resulting expression for hydraulic efficiency is simply the ratio of the time of the peak outflow concentration to the nominal residence time. The measure can thus be readily derived from RTD functions and does not have the problems associated with measurement of the mean residence time.

Fig. 5 gives an example of how the hydraulic efficiency factor can be used to compare different designs. In a study, thirteen hypothetical ponds with no vegetation and the same size were analysed with a computational fluid-dynamics model (Persson, 2000). It was shown that a subsurface berm or an island placed in front of the inlet improves the hydraulic performance concerning short-circuiting, effective volume and degree of mixing. Further, the study showed that a curved pond or an island placed near the side does not lead to lower hydraulic performance, and that the length-to-width ratio and the locations of in- and outlets have a considerable impact on the hydraulic performance.

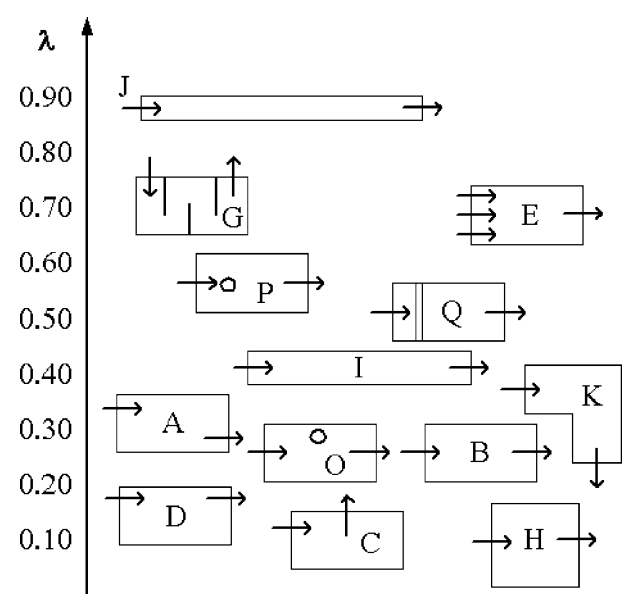

Fig. 5. Hydraulic efficiency of 13 ponds with different shapes and configurations. Case $\mathrm{P}$ and $\mathrm{O}$ contains an island, case $\mathrm{Q}$ has a subsurface berm, and case $\mathrm{G}$ has three berms.

\section{The effects of pond design on nitrogen removal}

To analyse the effects of different pond designs (Fig. 5) on nitrogen retention, a slightly modified version of the tanks-in-series model (Eq. (1)) was used. First, it was assumed that nitrogen retention is an area-based and temperature-dependent process (Arheimer and Wittgren, 2002):

$\frac{C_{\text {out }}}{C_{\text {in }}}=\left(\frac{1}{1+\left(\left(k_{\mathrm{aT}} A\right) / Q N\right)}\right)^{N}$

Furthermore, it is assumed that the definition of effective volume (Eq. (5)) may be written as in Eq. (14), i.e., that the effective volume is defined by an effective area and the actual depth of the pond:

$e=\frac{V_{\text {eff }}}{V_{\text {total }}}=\frac{A_{\text {eff }}}{A_{\text {total }}}=\frac{t_{\mathrm{m}}}{t_{\mathrm{n}}}$

Combining Eqs. (13) and (14) yields an area-dependent tanks-in-series model for nitrogen retention that includes both the effective volume (effective area) ratio, $e$, and the number of cells, $N$ :

$\frac{C_{\text {out }}}{C_{\text {in }}}=\left(\frac{1}{1+\left(\left(k_{\mathrm{aT}} e A_{\text {total }}\right) / Q N\right)}\right)^{N}$

The variables $e$ and $N$ have been estimated for the 13 design alternatives with a computational fluid-dynamics model (Table 1; Persson, 2000). It 
Table 1

Nitrogen removal of the 13 ponds of Fig. 5 and a reference pond ( $e=1$ and $N=1$ ) as calculated with Eqs. (15) and (16) and with the following assumptions: $C_{\mathrm{in}}=10 \mathrm{mgl}^{-1}, A_{\text {total }}=1$ ha, $Q=750 \mathrm{~m}^{3}$ per day and $T=10^{\circ} \mathrm{C}$

\begin{tabular}{llllll}
\hline Pond & $e$ & $N$ & $\begin{array}{l}C_{\text {out }} \\
\left(\mathrm{mg} \mathrm{l}^{-1}\right)\end{array}$ & \multicolumn{2}{l}{\begin{tabular}{l} 
Nitrogen removal \\
\cline { 5 - 6 }
\end{tabular}} \\
\cline { 5 - 6 } & & & & $\begin{array}{l}\text { (kg ha } \\
\text { per year })\end{array}$ & $(\%)$ \\
\hline Reference & 1.00 & 1.00 & 9.70 & 815 & 3.0 \\
A & 0.74 & 0.73 & 9.78 & 605 & 2.2 \\
B & 0.79 & 0.61 & 9.77 & 643 & 2.3 \\
C & 0.46 & 0.28 & 9.86 & 374 & 1.4 \\
D & 0.34 & 0.50 & 9.90 & 281 & 1.0 \\
E & 0.89 & 8.20 & 9.73 & 736 & 2.7 \\
G & 1.00 & 11.00 & 9.70 & 826 & 3.0 \\
H & 0.44 & 0.23 & 9.87 & 357 & 1.3 \\
I & 1.00 & 1.70 & 9.70 & 820 & 3.0 \\
J & 1.00 & 34.00 & 9.70 & 826 & 3.0 \\
K & 0.78 & 1.10 & 9.77 & 640 & 2.3 \\
O & 0.73 & 1.60 & 9.78 & 602 & 2.2 \\
P & 0.96 & 2.10 & 9.71 & 789 & 2.9 \\
Q & 0.93 & 1.00 & 9.72 & 759 & 2.8 \\
\hline
\end{tabular}

should be noted that the effective volume ratios are too high to be realistic. This is also the case of the $N$-values, since $N$ cannot be less than 1 . It should, however, be emphasised that the simulations are not calibrated against any existing ponds, and are only showing how large effect different designs has in relation to each other. They are to be regarded as relative values aiming at compare different layouts. The average nitrogen removal coefficient, $k_{\mathrm{aT}}$, has been estimated for Swedish ponds by Arheimer and Wittgren $(1994,2002)$ :

$k_{\mathrm{aT}}=k_{\mathrm{a}} T=0.0023 \mathrm{~m} \mathrm{~d}^{-1}{ }^{\circ} \mathrm{C}^{-1} T$

Assuming an incoming nitrogen concentration, $C_{\text {in }}$, of $10 \mathrm{mg}^{-1}$; a pond area, $A_{\text {total }}$, of 1 ha; a flow, $Q$, of $750 \mathrm{~m}^{3}$ per day; and an average temperature, $T$, of $10^{\circ} \mathrm{C}$, then nitrogen removal may be calculated according to Table 1. Furthermore, although not explicit in the calculations, a depth, $h$, of $1.5 \mathrm{~m}$ was assumed (Persson, 2000) which gives a nominal residence time, $t_{\mathrm{n}}$, of 2 days, which may be considered a minimum for Eqs. (13) and (15) to be valid (Arheimer and Wittgren, 2002).

It can be seen in Table 1 that outgoing concentrations do not vary a lot, but removal still varies with a factor 3 between 281 and $826 \mathrm{~kg} \mathrm{ha}^{-1}$ per year. This reflects the permanent problem of measuring nitrogen removal, being the difference between two large numbers, i.e., incoming and outgoing amounts. If we assume that we had measured the nitrogen removal in the 13 ponds as they are calculated in Table 1, but then used Eq. (15) without taking effective area or dispersion into consideration, i.e., used $e=1$ and $N=1$. Then, consequently, we would have calculated removal rate coefficients down to three times lower $\left(k_{\mathrm{a}}=0.0008 \mathrm{~m}\right.$ per day per degree Celsius for pond D) than for the most effective ponds $\left(k_{\mathrm{a}}=0.0023 \mathrm{~m}\right.$ per day per degree Celsius for ponds G, I and J). It is therefore reasonable to assume that part of the difference between removal rate coefficients reported in the literature is due to differences in effective area and/or mixing, since these factors are not usually taken into consideration.

Furthermore, it can be concluded from Eq. (15) and Table 1 that effective area is more important for the estimation of removal rate coefficients than the degree of mixing. This is further illustrated for relative nitrogen removal in Figs. 6 and 7 where $e$ and $N$, respectively, are kept constant at 1 while letting the other vary according to Table 1. This confirms what has been put forward by, e.g., Reed et al. (1995), who states that a model based on plug flow gives results similar to those of the tanks-in-series model.

Figs. 6 and 7 also show that the effect of $e$ and $N$ on relative nitrogen removal increases if the removal rate coefficient, $k a$, increases (in this case by a factor 10).

Since the focus in this article is on nitrogen removal, the first-order kinetics was chosen. But the same principles apply to removal of suspended solids. In Eq. (3) it is shown that the removal efficiency is a function of flow and area, both of which are linked to hydraulic and hydrological conditions. This means that changes in the effective volume (area) ratio will affect the removal efficiency. This has also been verified in field measurements where a circular stormwater pond with low effective volume ratio had much lower removal efficiency than expected in view of its size (Pettersson, 1999). In another research project, a correlation was found between the removal efficiency in stormwater ponds and the hydraulic efficiency as defined in Eq. (11) (German, 2003).

The investigation of the importance of dispersion and effective volume ratio also questions a definition of hydraulic efficiency, which is based on an equal 


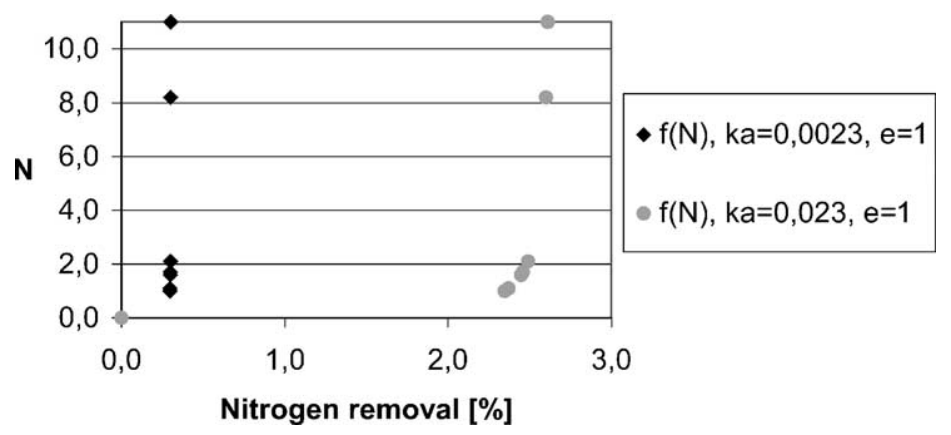

Fig. 6. The relative nitrogen removal as a function of degree of dispersion, $N$, while effective volume (area) ratio; $e$, is kept constant at 1 (Eq. (15) and data from Table 1). Unrealistic $N$-values below 1, has been removed, as well as high $N$-values above 10.

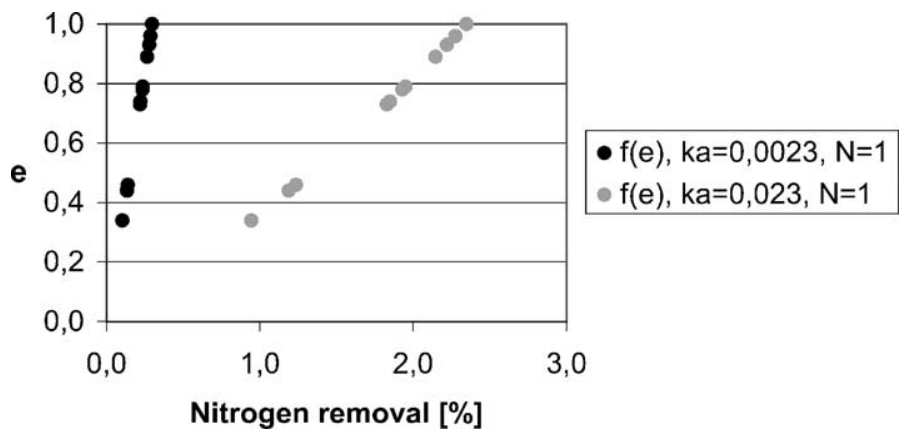

Fig. 7. The relative nitrogen removal as a function of effective volume (area) ratio, $e$; while degree of dispersion, $N$, is kept constant at 1 (Eq. (15) and data from Table 1).

weight between the two factors. This since the effective volume ratio seems to be the dominant factor in relation to dispersion. However, there are several arguments that must be considered before placing hydraulic efficiency and effective volume ratio on an equality, as proposed by Thackston et al. (1987).

1. The intention with the method is that it should categorise ponds that aim to remove soluble pollutants, e.g., nitrogen, as well as suspended solids. Therefore, more research has to be made that investigate relations between removal efficiency of suspended solids and hydraulic efficiency.

2. To relate peak time instead of mean residence time to the nominal residence time still have the significant advantage that one does not has to consider the tail of the RTD-function.

3. The result is based on the first-order-kinetic model, which does not include damage on biofilms or resuspension. Therefore, it is possible that extreme short-circuiting with concentrated flow could be an influential factor.

\section{Conclusions}

The hydraulic conditions can be analysed through the concepts of effective volume ratio and dispersionthe first describing how much of the total volume (area) is used, and the second the degree of mixing. In ponds the effective volume ratio is primarily determined by the length-to-width ratio, while the dispersion is primarily determined by length-to-width ratio and to some degree by depth and flow velocity. In more complex ponds, however, factors such as inand outlet, vegetation or topography can have major effects on the hydraulic conditions.

It can also be concluded that dispersion has a marginal effect on nitrogen removal. The most important factor that determines hydraulic condition is 
instead the effective volume ratio. This implies that a model based on plug flow would give similar result as a thank-in-series model.

A method of comparing different design solutions with each other is to use the hydraulic efficiency factor, which is defined by the time of the peak outflow concentration divided by the nominal residence time. This definition gives, however, dispersion and effective volume ratio the same weight. Looking at nitrogen removal, according to the first-order kinetic model, the dispersion factor perhaps ought to be less weighted.

\section{Acknowledgements}

The authors wish to thank the Swedish Foundation for Strategic Environmental Research (MISTRA) and The Swedish Association of Graduate Engineers (CF) for financial support.

\section{References}

Arceivala, S.J., 1981. Hydraulic modeling for waste stabilization ponds. ASCE J. Envion. Eng. Div. 109 (EE1), 265-268.

Arheimer, B., Wittgren, H.B., 1994. Modelling the effects of wetlands on regional nitrogen transport. Ambio 23, 378-386.

Arheimer, B., Wittgren, H.B., 2002. Modelling nitrogen removal in potential wetlands at the catchment scale. Ecol. Eng. 19, 63-80.

EPA 1986. Methodology for analysis of residence basins for control of urban runoff quality. US Environmental Protection Agency, EPA 440/5-87-001, September 1986.

Fischer, H.B., 1967. The mechanics of dispersion in natural streams. ASCE J. Hyd. Div. 93 (6), 187-216.
Fogler, H.S., 1992. Elements of Chemical Reaction Engineering, second ed., Prentice-Hall, Englewood Cliffs, NJ, 838 pp.

German, J., 2003. Reducing Stormwater Pollution. PhD thesis. Chalmers University, Göteborg, Sweden.

Kadlec, R.H., Knight, R.L., 1996. Treatment Wetlands. CRC Press/Lewis Publishers, Boca Raton, Florida.

Nameche, T.H., Vasel, J.L., 1998. Hydrodynamic studies and modelization for aerated lagoons and waste stabilization ponds. Water Res. 32, 3039-3045.

Persson, J., 2000. The hydraulic performance of ponds of various layouts. J. Urban Water 2/3, 243-250.

Persson, J., 2001. How hydraulic conditions enhance water quality in wetlands. Paper presented at the conference New Wetlands in Agricultural Areas-Restoration, Construction and Impact on Nutrient Reduction and Biodiversity. 10-11 May 2001, Lund, Sweden.

Persson, J., Somes, N.L.G., Wong, T.H.F., 1999. Hydraulic efficiency of constructed wetlands and ponds. Water Sci. Technol. 40, 291-299.

Pettersson, T., 1999. Stormwater Ponds for Pollution Reduction. $\mathrm{PhD}$ thesis. Chalmers University, Göteborg, Sweden.

Polprasert, C., Bhattarai, K.K., 1985. Dispersion model for waste stabilization ponds. ASCE J. Environ. Eng. Div. 111, 45-59.

Reed, S.C., Crites, R.W., Middlebrooks E.J., 1995. Natural Systems for Waste Management and Treatment, second ed. McGraw-Hill, New York.

Somes, N.L.G., Fabian J., Wong, T.H.F., 1998. Tracking pollutant residence in contructed stormwater wetlands. In: Proceedings of the UDM 98-Fourth International Conference on Developments in Urban Drainage Modelling. 21-24 September 1998, London, UK.

Thackston, E.L., Shields Jr., F.D., Schroeder, P.R., 1987. Residence time distributions of shallow basins. J. Environ. Eng. 113, 1319-1332.

Werner, T.M., Kadlec, R.H., 2000. Stochastic simulation of partially-mixed, event-driven treatment wetlands. Ecol. Eng. 14, 253-267.

Wong, T.H.F., Somes, N.L.G., 1995. A stochastic approach to designing wetlands for stormwater pollution control. Water Sci. Techol. 32, 145-151. 